Case Study

\title{
Effects of 4 weeks of dynamic neuromuscular stabilization training on balance and gait performance in an adolescent with spastic hemiparetic cerebral palsy
}

\author{
Do-Hyun Kim, PT, MS ${ }^{1)}$, Duk-Hyun An, PT, PhD²), Won-Gyu Yoo, PT, $\mathrm{PhD}^{2)^{*}}$ \\ 1) HIP\&MAL Laboratory, Department of Rehabilitation Science, Inje University, Republic of Korea \\ 2) Department of Physical Therapy, College of Biomedical Science and Engineering, Inje University: \\ 197 Inje-ro, Gimhae, Gyeongsangnam-do 621-749, Republic of Korea
}

\begin{abstract}
Purpose] The purpose of this study investigated the effects of 4 weeks of dynamic neuromuscular stabilization training on balance ability. [Subject and Methods] An adolescent with spastic hemiparetic cerebral palsy was recruited. The subject performed 4 weeks of dynamic neuromuscular stabilization training. We assessed the balance subtest of the Bruininks-Oseretsky Test of Motor Proficiency-Second Edition, the 10-meter walk test, and the 6-min walk test. [Results] The balance subtest scores were improved significantly after training. [Conclusion] This study suggests that 4 weeks of dynamic neuromuscular stabilization training is effective for improving balance and gait performance in spastic hemiparetic cerebral palsy.

Key words: Balance, Cerebral palsy, Gait
\end{abstract}

(This article was submitted Jun. 12, 2017, and was accepted Jul. 7, 2017)

\section{INTRODUCTION}

Conventionally, balance control is often measured by balance tools, including the Pediatric Balance Scale (PBS). However, measurement balance using such assessment tools has shown floor and ceiling effects ${ }^{1)}$. The balance subtest of the Bruininks-Oseretsky Test of Motor Proficiency-Second Edition (BOT-2) has been shown to be superior for evaluating high-level balance ability ${ }^{2}$. The 10-meter walk test (10MWT) and 6-min walk test (6MWT) can be used to obtain clinical information related to gait performance. Excellent and acceptable test-retest reliability has been observed using the 10MWT $(0.81)$ and 6MWT $(0.98)$ in children with cerebral palsy $(\mathrm{CP})^{3)}$. The dynamic neuromuscular stabilization (DNS) technique involves involuntarily activating the diaphragm with deep abdominal muscles prior to purposeful movement in humans via feedforward feedback ${ }^{4}$. Despite the importance of motor control of the trunk muscles, there is a dearth of evidence on the effects of trunk stabilization training using the DNS technique on balance and gait ability. Thus, the purpose of this research was to investigate the effects of 4 weeks of DNS training on balance and gait ability in an adolescent with spastic hemiparetic CP.

\section{SUBJECT AND METHODS}

The subject was a 13-year-old adolescent, delivered normally at 38 weeks gestation. Brain magnetic resonance imaging (MRI) showed a deep white matter ischemic lesion near the lateral ventricle. His primary problems were asymmetric standing balance and muscle weakness of the hip extensor and ankle dorsiflexor. Informed consent was obtained from his caregiver

*Corresponding author. Won-Gyu Yoo (E-mail: won7y@inje.ac.kr)

(C2017 The Society of Physical Therapy Science. Published by IPEC Inc.

(c) $(-)$ This is an open-access article distributed under the terms of the Creative Commons Attribution Non-Commercial No Deriva-

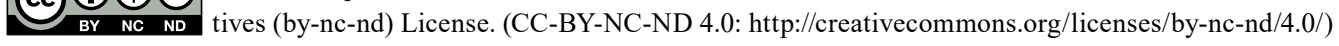


before the study. Ethics approval was obtained from the Inje University Ethics Committee for Human Investigations, and written informed consent was obtained from the participant. The balance subtest of the BOT-2 consists of nine items: (1) standing with feet apart on a line with vision, (2) walking forward on a line, (3) standing on one leg on a line with vision, (4) standing with feet apart on a line without vision, (5) walking forward heel-to-toe, (6) standing on one leg on a line without vision, (7) standing on one leg on a balance beam with vision, (8) standing heel-to-toe on a balance beam, and (9) standing on one leg on a balance beam without vision. Initially, each item was measured as a raw score and then a point score was calculated. Prior to obtaining the raw data, the participant was familiarized with the balance test procedures. The subject positioned his toes behind the start line and was asked to walk as fast as possible until a stop signal was given at the 5-m finish line. A rater recorded the subject's $10 \mathrm{~m}$ walking time with a stopwatch. The subject was allowed two practice trials and then performed three test trials. He was asked to walk as far as possible in a rectangular area $(20 \times 45 \mathrm{~m})$ during $6 \mathrm{~min}$. A rater provided verbal encouragement, i.e., 'keep it up', every $30 \mathrm{~s}$ and measured the subject's cumulative 6-min walking distance. The patient underwent 4 weeks of rehabilitation training using DNS techniques. DNS training involves a downward action of the diaphragm during inhalation, which controls intra-abdominal pressure (IAP) in combination with the transverse abdominalis (TrA), multifidus and the pelvic floor muscle, but with little activation of the rectus abdominis (RA) or external oblique (EO). Successful interventional DNS tasks were: (1) 'catching' of the breath through deep breathing, (2) neutralization of thorax movements, (3) inhalation for lowering the diaphragm, and coactivating the TrA and pelvic floor muscle while maintaining neutral and caudal alignment.

\section{RESULTS}

The score on the \# BOT-2 balance subtest improved, from 30 to 34 points, post-intervention. In particular, scores were increased on items 5 (by 50\%; from 2 to 4 ), 7 (by 25\%; from 2 to 3), and 9 (by 25\%; from 3 to 4 ). The $10 \mathrm{MWT}$ time was reduced, from $8.54 \mathrm{~s}$ to $6.67 \mathrm{~s}$, and the $6 \mathrm{MWT}$ distance was increased, from $478.6 \mathrm{~m}$ to $544.1 \mathrm{~m}$.

\section{DISCUSSION}

The purpose of this study was to assess the effects of DNS rehabilitation training on balance and gait ability in an adolescent with hemiparetic CP. The results showed that scores on the balance subtest of the BOT-2, the 10MWT, and the 6MWT were all improved after the intervention compared with the baseline. Most importantly, the score on the BOT-2 subtest was increased from 30 to 34 points (13.2\%). Our results are consistent with a previous study that showed a reduction in mean center of gravity (COG) sway velocity and improvement in the limit of stability (LOS) after 3 weeks of DNS-based intervention in a patient with Charcot-Marie-Tooth disease ${ }^{5)}$. The 10MWT time was reduced from 8.54 to $6.67 \mathrm{~s}(28.0 \%)$ and the 6MWT distance was improved from $478.6 \mathrm{~m}$ to $544.1 \mathrm{~m}(13.8 \%)$. Similarly, Morgan et al. showed a positive relationship between gait speed and balance test performance $\left.(\mathrm{r}=0.647, \mathrm{p}<0.01)^{6}\right)$. Our results indicate that 4 weeks of DNS training is effective for improving balance and gait ability in ambulant $\mathrm{CP}$ patients.

\section{REFERENCES}

1) Franjoine MR, Darr N, Held SL, et al.: The performance of children developing typically on the pediatric balance scale. Pediatr Phys Ther, 2010, 22: 350-359. [Medline] [CrossRef]

2) Bruininks RH: Bruininks-Oseretsky Test of Motor Proficiency, (BOT-2). Minneapolis: Pearson Assessment, 2005.

3) Thompson P, Beath T, Bell J, et al.: Test-retest reliability of the 10-metre fast walk test and 6-minute walk test in ambulatory school-aged children with cerebral palsy. Dev Med Child Neurol, 2008, 50: 370-376. [Medline] [CrossRef]

4) Kolar P, Sulc J, Kyncl M, et al.: Stabilizing function of the diaphragm: dynamic MRI and synchronized spirometric assessment. J Appl Physiol 1985, 2010, 109: 1064-1071. [Medline] [CrossRef]

5) Kobesova A, Kolar P, Mlckova J, et al.: Effect of functional stabilization training on balance and motor patterns in a patient with Charcot-Marie-Tooth disease. Neuroendocrinol Lett, 2012, 33: 3-10. [Medline]

6) Morgan P, Murphy A, Opheim A, et al.: Gait characteristics, balance performance and falls in ambulant adults with cerebral palsy: An observational study. Gait Posture, 2016, 48: 243-248. [Medline] [CrossRef] 